\title{
Rod Outer Segment
}

National Cancer Institute

\section{Source}

National Cancer Institute. Rod Outer Segment. NCI Thesaurus. Code C12639.

A portion of the retinal rod cell largely consisting of a stack of discs (membrane infoldings that are incompletely separated in cones) that are continually replenished near the inner segment and that are shed from the distal end and phagocytosed by the pigmented epithelium. 